\title{
El paisaje desterritorializado o multiterritorial. Una mirada desde la obra "Fuera de lugar" de Edward Said
}

\author{
The deterritorialized or multiterritorial landscape. A point of view from \\ the work "Out of place" by Edward Said
}

\section{A paisagem desterritorializada ou multiterritorial. Um olhar da obra "Fora do lugar" de Edward Said}

\section{Juan Cruz Ramón Margueliche}

Instituto de Investigaciones en Humanidades y Ciencias Sociales. Facultad de Humanidades y Ciencias de La Educación. Universidad Nacional de La Plata. Buenos Aires. Argentina

\author{
jcruzmargueliche@gmail.com
}

Código ORCID: https://orcid.org/0000-0002-1678-2858

\begin{abstract}
RESUMEN
Fuera de Lugar se publicó por primera vez en el año 1999 y por su contenido podría haber formado parte del prólogo de Orientalismo (1978), una de sus obras más destacadas. En Fuera de lugar Said corporiza y materializa sus postulados vertidos en la obra Orientalismo, pero lo hace a través de una propuesta de un yo - autobiográfico. Es a partir de sus diferentes desplazamientos: viajes, traslados y exilios (voluntarios o forzados), que se disponen para el autor como verdaderos itinerarios transculturales (Clifford, 1999). Esta dinámica de vida le permitió no solo constituirse como sujeto (transitar pasajes etarios) sino como un escritor - habitante de los espacios siempre en situación de tensión entre identidades complejas e híbridas que buscaban (des) legitimarse. Se podría decir que Said supo (sobre) vivir a través de la movilidad permanente, siendo un sujeto en una constante búsqueda de autoidentificación. Se trabajará esta obra a través de los conceptos de paisaje y de desterritorialización para poder entender la trayectoria de vida de Said y sus configuraciones culturales en un espacio que ya no respondía a la tradicional estructura de representación que (todavía) impone el Estado - Nación.
\end{abstract}

\begin{abstract}
Out of Place was published for the first time in 1999 and based on its content, it could have been part of the prologue of "Orientalism" (1978), one of Said's masterpieces. In Out of Place, Said materialises and brings to life his postulates written in Orientalism, but he does so from an autobiographical-I place. It is through his different journeys: travels, moves and exiles (voluntarily or not) that the author displays as true transcultural itineraries (Clifford, 1999). This way of life allowed him not only to constitute himself as a subject (to transit age passages), but also as a writer-resident of the places that were always in tension between complex and hybrid situations that were looking to (de) legitimise himself. It could be pointed out that Said knew how to live through the permanent mobility, being a subject in a constant search of auto identification. We will work this piece through the concepts of landscapes and deterritorialization in order to understand Said's life and its cultural configurations in a place that no longer responded to the traditional structure of representation that the Nation-Estate (still) imposes.
\end{abstract}




\section{RESUMO}

Fora do lugar foi publicado pela primeira vez em 1999 e seu conteúdo poderia ter sido parte do prólogo de Orientalismo (1978), um de seus trabalhos mais notáveis. Em Fora do lugar Said incorpora e materializa seus postulados vertidos na obra Orientalismo, mas o faz através de uma proposta autobiográfica. São seus diferentes deslocamentos, viagens, transferências e exílios (voluntários ou forçados), que estão disponíveis para o autor como verdadeiros itinerários transculturais (Clifford, 1999). Essa dinâmica da vida permitiu - Ihe não só constituir - se como sujeito (trânsitar diferentes idades), mas tambén como escritor - habitante de espaços sempre em situação de tensão entre identidades complexas e híbridas que buscavam serem (não) legitimadas. Pode-se dizer que Said sabia (sobre) viver de mobilidade permanente, sendo um sujeito em constante busca de autoidentificação. O trabalho de Said será analisado através dos conceitos de paisagem e desterritorialização, a fim de compreender a trajetória da sua vida e suas configurações culturais em um espaço que já não responde à estrutura de representação tradicional que (ainda) impõe o Estado - Nação.

PALABRAS CLAVE: Paisaje; desterritorialización; multiterritorialidad; Occidente y Nación.

KEYWORDS: Landscape; deterritorialization; multi-territoriality; western world and Nation.

PALAVRAS-CHAVE: Paisagem; desterritorialização; multiterritorialidade; Ocidente e Nação.

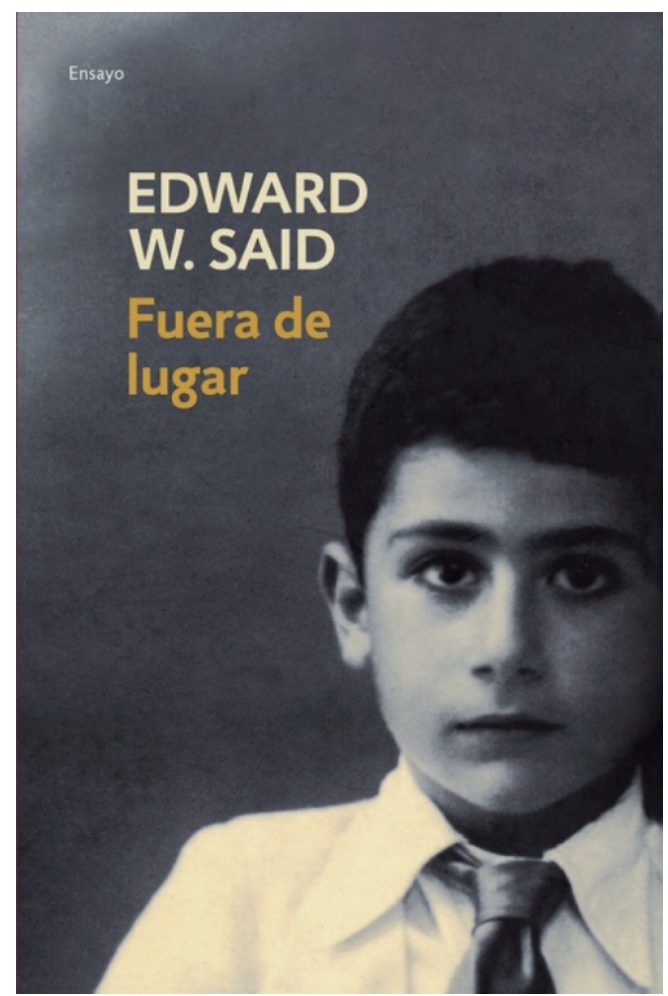

Figura 1 - Tapa del libro Fuera de Lugar de Edward Said (1999, 2001)

\section{Introducción}

Edward W. Said (1935-2003), nació en Jerusalén cuando todavía no se había efectuado la partición territorial de Palestina (1947) ni tampoco la creación del Estado de Israel (1948). Su vida transcurrió por diferentes lugares y territorios como Palestina, Líbano, Egipto y Estados Unidos. En esos desplazamientos, su vida fue sufriendo desafiliaciones territoriales permanentes donde identidad y espacio se encontraban en constante tensión. La obra Fuera de Lugar se publicó por primera vez en el año 1999 y por su contenido podría haber formado parte del prólogo de Orientalismo (1978), una de sus obras más destacadas. En Fuera de lugar Said corporiza y materializa sus postulados vertidos en la obra Orientalismo, pero lo hace a través de una propuesta de un yo - autobiográfico. En esta "literatura del yo" el autor nos marcará el camino (metodología) para llevar adelante este trabajo. Para Carreras (2016) las biografías 
se configuran como un género de carácter híbrido que se desarrollan en los límites de la historia y la ficción. Esta autora nos aclara que, si pretendemos estudiar las biografías como historia o como ficción, no debemos olvidar la esencia misma de este género (textos fronterizos). En este sentido, Fuera de lugar a través de su protagonista Edward Said se nutre de una potente obra donde logra plasmar partes de sus trabajos académicos previos. Por un lado, fue el trabajo de desmontaje del discurso construido por la empresa colonial de la tríada franco-anglo-norteamericana que nos expone en Orientalismo. Y en este caso, en la manifestación de esa metanarrativa de esquema global que empieza a cuestionarse en la propia vida de Said.

Ese Oriente que para ser conocido (por Occidente) debió ser orientalizado es parte del contexto de vida que siente Said formar parte. La construcción e imposición discursiva genera diferentes espacialidades dotadas de exotismos que se transfieren a sus actores y a las formas de habitar el mundo. Es a partir de sus diferentes desplazamientos: viajes, traslados y exilios ${ }^{1}$ (voluntarios o forzados), que se disponen para el autor como verdaderos itinerarios transculturales (Clifford, 1999). Esta dinámica de vida le permitió no solo constituirse como sujeto (transitar diferentes pasajes etarios) sino como un escritor - habitante de los espacios siempre en situación de tensión entre identidades complejas e híbridas que buscaban (des) legitimarse para hacerse o encontrar un lugar. Se podría decir que Said supo (sobre) vivir a través de la movilidad permanente, siendo un sujeto en una constante búsqueda de autoidentificación. El tema que trata la obra es aún un tópico actual en los debates culturales y políticos, ya que nos interpela en la relación que tienen los actores con su entorno y a su vez con la identificación que encuentran en la representación de su paisaje.

Se trabajará esta obra a través de los conceptos de paisaje y de desterritorialización para poder entender la trayectoria de vida de Said y sus configuraciones culturales en un espacio que ya no responde a la tradicional estructura de representación que (todavía) impone el Estado - Nación. En las fronteras propias que Said va construyendo por debajo de la cultura dominante en la que vive, podemos encontrar intersticios espaciales e identitarios que nos permiten entender tramas relacionales, más que posturas antagónicas. El discurso orientalista ha podido sobrevivir y funcionar en la sociedad Occidental gracias a la riqueza de la red que lo forma y eso queda demostrado en la misma mirada que Said recibe y percibe en los diferentes territorios que lo acobijan (o rechazan). En Fuera de lugar, se da una superposición de inconsistencias entre la identidad, la cultura y el territorio. En ese sentido, podemos mencionar tres inconsistencias:

1. La inducida por el colonialismo externo: el discurso orientalista se espacializa a través de la presencia formal y fáctica de la fuerza colonial que impone una estructura política - cultural sin reconocer las estructuras preexistentes.

2. La inducida por el colonialismo interno: a través de la educación e imposición del lenguaje colonial generando núcleos difusores de la cultura dominante.

3. La inducida por la implementación de nuevas fronteras culturales: la creación de diferentes fronteras culturales tanto las diseñadas por los actores hegemónicos como aquellas producidas a partir de la acción de los diferentes actores subalternos.

En este sentido, el objetivo del trabajo es discutir la categoría de paisaje como espacio de construcción y representación en la vida del autor. Un paisaje que se construye en diferentes trayectorias y desplazamientos configurando procesos de desterritorialización y de multiterritorialidad que influyen en la conformación de

1 "Su condición de exiliado, primero en Egipto y luego en Estados Unidos, le ha concedido, como compensación personal, la fructuosa marginalidad de quien, en razón de las circunstancias, acampa en una zona fronteriza, en la periferia de Occidente y del Oriente Próximo, desde la que contempla su cultura a la luz de otras culturas, y su lengua, a la luz de otras lenguas. Conocedor profundo de la literatura e historiografía anglosajonas y francesas y de las claves de la dominación imperialista de Occidente sobre el mundo arabomusulmán, ha podido examinar a este a la vez con intimidad y a distancia, con amor, pero sin indulgencia". (Said, 2002:13). 
una identidad y cultura particular. En este sentido, debemos reparar en algunas reflexiones sobre dichos conceptos. Los conceptos que aquí se presentarán derivan de filiaciones teóricas diferentes. Cada uno de ellos emerge en un campo teórico que posee su propia geografía. Los conceptos y las teorías surgen en un lugar y problemática específica que más tarde o temprano se generalizan abstrayéndose del lugar de origen. Por lo cual no debemos perder de vista su génesis y trayectoria configurativa. Esta propuesta nos invita a repensar la relación entre la teoría y el campo de lo empírico para no realizar ejercicios de transferencia forzados. No obstante, trataremos de acercar algunas líneas de las trayectorias de estos conceptos, pero alertando a los/as lectores/as que se requiere de un mayor espacio de indagación para construir una génesis configurativa de cada uno de ellos.

Por último, también se asiente que conceptos como cultura (el cual Said trabajó de manera brillante y apasionadamente) han sido trabajadas por el autor a partir de estrategias de (de) construcción de los discursos dominantes a través de diferentes plataformas enunciativas (novelas, prensa, poesía, académicos/as, entre otros). Para Said “(...) las ideas, las culturas y las historias no se pueden entender ni estudiar seriamente sin estudiar al mismo tiempo su fuerza o, para ser más precisos, sus configuraciones de poder" (Said, 2002:25). Para este autor, la cultura es un concepto que incluye un elemento de refinada elevación donde se reúnen en un archivo lo mejor que cada sociedad ha construido. No obstante, nos aclara que con el tiempo la cultura llega a asociarse a veces de manera agresiva con la Nación o el Estado: esto es lo que "nos" hace diferente de los otros (Said, 2018). La cultura es además una fuente de identidad (una fuente bien beligerante nos advierte) como a veces se ve en los retornos a la cultura o la tradición. En este sentido, acompañan además a estos "retornos" códigos rigurosos de conducta intelectual y moral. Pero Said afirma que la cultura es además una especie de teatro en el cual se enfrentan diferentes causas políticas e ideológicas.

En este trabajo parecerá que la temática cultural tuvo un tratamiento tangencial. En este sentido se buscó visibilizar como la cultura colonial intentó hegemonizar y homogeneizar las culturas autóctonas a través de diferentes dispositivos (planificados o no) en los distintos lugares en que Said desplegó su vida. Es en la obra de "Cultura e Imperialismo" (1993) donde podemos encontrarnos con una gran riqueza de indagación sobre esta categoría. La estructura del trabajo nos insta a través de este yo - autobiográfico de Said a reconstruir el camino ensayístico - académico que propone e invita el autor. Por ello, planteamos una mirada complementaria con los conceptos que a continuación irán encontrándose en los apartados posteriores.

\section{Said: una vida en movimiento}

En este apartado se trabajará en base a la narración e historia de vida que Said plasma en la obra Fuera de lugar. En apartados posteriores retomaremos este material para enmarcar su biografía en categorías de análisis.

Said se había marchado de Palestina en el año 1947. Al volver después de muchos años a su tierra natal, los funcionarios de Israel le hacen una pregunta de rutina en el ingreso al país. Su pasaporte decía que provenía de Estados Unidos e indicaba que había nacido en Talbiyah, (Jerusalén Occidental). A partir de esta situación peculiar le hacen la siguiente pregunta: ¿En qué momento exacto después de nacer se había marchado de Israel? Said respondía que se había marchado en el año $1947^{2}$ de "Palestina" haciendo énfasis en la palabra Palestina. Esta pregunta tiene dos aristas diferentes pero complementarias. La primera hace referencia al conflicto Israel - Palestina y la segunda a la situación política-identitaria que marca cierta adscripción y desafiliación territorial por parte de Said y de los palestinos. La

2 Los británicos se retiran de Palestina en 1948, cuando Said y su familia ya no estaban. 
salida de Palestina configuró un punto de partida en la vida de Said. Una vida de desplazamientos constantes y con ello una particular forma de relacionarse con sus entornos. Producto de sus desplazamientos, nunca supo qué idioma habló primero, si el árabe o el inglés, o cuál era su (propio) idioma. "Pero lo que sí sé es que los dos han estado siempre juntos en mi vida, una resonando en el otro, a veces de forma irónica, a veces con nostalgia, casi siempre comentándose y corrigiéndose el uno al otro" (Said, 1999, 2001: 18).

"Todas las familias inventan a sus padres y a sus hijos, les confieren una historia, una identidad, un destino y hasta un idioma. Siempre hubo algún error en el modo en que fui inventado y supuestamente debía encajar en el mundo de mis padres y mis cuatro hermanas. Durante la mayor parte de mi infancia y mi juventud no fui capaz de averiguar si esto se debía a que yo malinterpretaba continuamente mi papel o por culpa de algún defecto profundo de mi ser (...) En otras ocasiones me daba la impresión de que carecía por completo de personalidad, de que era tímido, inseguro y falto de voluntad. Sin embargo, mi sensación dominante era que siempre estaba fuera de lugar" (Said, 2001:17).

Hasta 1947 los viajes ocasionales a Palestina tenían un carácter totalmente familiar en el marco de su clan (khlei fawi). Pero después de la segunda guerra mundial sus visitas a Jerusalén constituían un escape del régimen disciplinario que se estaba formando a su alrededor en El Cairo ${ }^{3}$. Pero a pesar de cobrar mayores cuotas de libertad en sus visitas a Jerusalén, su vida seguía desarrollándose en numerosos itinerarios que lo mantenían encerrado. Solo los libros y el cine le otorgaban a Said otro tipo de libertad a través de fantasías e imaginación.

El recuerdo que tiene Said de su Palestina natal al comienzo es arbitrario ya que en la actualidad no existe como tal la concibió. Es un recuerdo desdibujado cubierto de deseos y nostalgias que no encuentran reparo en sus viajes venideros. Ese lugar de la infancia lo revive a lo largo de su obra de manera ambivalente entre la nostalgia y la autocrítica. La configuración de sus recuerdos se va desdibujando con las transformaciones acaecidas a lo largo del tiempo de sus ausencias. En cambio, en Egipto vivía una realidad más tangible. Al carecer de contactos reales, la familia de Said logró desarrollar una cohesión interna mucho mayor como estrategia de supervivencia. En este sentido, el espacio de la infancia pivoteaba con otros lugares materiales en la ciudad del Cairo.

En El Cairo, su formación y crianza se daba en un contexto muy diferente. Said se encontraba inserto en una comunidad homogénea de comerciantes y profesionales acaudalados. Pero los contextos educativos, de ocio y espacios de estatus social más allá de conformar un espacio homogéneo también configuraban un espacio hegemónico. Su trayectoria dentro de esta comunidad receptora formada por su mayoría de extranjeros (ingleses) se circunscribió a un segmento dentro de un entorno más amplio e interconectado: la escuela, la iglesia, el club, el jardín y su casa. Su vida se espacializaba en un pequeño mundo plagada de piezas culturales y políticas a diferentes escalas. Pero en todas ellas, se encontraba relegado a una asimetría constante. Frente a él, un "otro" que lo desterraba de ese nosotros de pertenencia.

En la escuela del Cairo, Said recibió una educación formal rodeado de compañeros y compañeras de nacionalidad británica en su mayoría. Desde 1941 - 1946 nunca tuvo maestros egipcios que le impartieran clases, ni tampoco fue consciente de ninguna presencia árabe - musulmana en la escuela. En este contexto Said claramente se encontraba fuera de lugar y lograba solo encontrar (se) su lugar en pequeños espacios de aislamiento. La búsqueda de actividades escapistas le permitían salir de esas situaciones.

3 Said se formó en una escuela de enseñanza inglesa en la ciudad del Cairo. En esa época de guerra con la ciudad el paisaje estaba dominado por las tropas británicas, y por ende por la cultura imperial del mismo. 
Para Zapata (2008), Said describe la experiencia de un sujeto oriental en las nuevas metrópolis mundiales. Se pregunta ¿Cómo Said se enfrenta a tener que ser señalado como un otro, a veces de manera paternalista y otras de manera violenta? Para la autora, es visto como un palestino: mítico, exótico y observable. Said recibe la educación refinada de cuño británico en El Cairo durante los años ' 40 por formar parte de una familia acomodada en la colonia. "Aunque me enseñaron a creer y pensar como alumno inglés, también me enseñaron a comprender que era extranjero, un Otro no europeo, educado por mis superiores a entender mi condición y no aspirar a ser británico" (Said, en Zapata, 2008:57). Para Said, el problema no es el contacto, sino la forma en que éste se produce ya que el conflicto no se radica en el cambio cultural sino en el tipo de relaciones que lo producen (Zapata, 2008).

En El Cairo, Said remarca una fuerte distinción social y de poder. El Cairo como colonia inglesa, reproducía la relación del buen ciudadano: el inglés. Y por el otro lado, constituía la barrera diferenciadora de los súbditos. A partir de esta distinción también surgen las categorías de los intrusos, extraños y extranjeros.

El establecimiento educativo en la vida de Said fue la escuela primaria Gezira Preparatory School (GPS) la cual le acercó su primera experiencia de un sistema organizado como negocio colonial por los británicos. Es decir, le proporcionó su primer contacto con la autoridad colonial: “(...) aunque algunos niños y niñas de la GPS creían que éramos egipcios, había en nosotros (y particularmente en mí) algo extemporáneo y fuera de lugar, aunque todavía no sabía por qué" (Said, 2001:67). En el período educativo de la secundaria, Said en calidad de hijo de hombre de negocios norteamericano y sin la más mínima impresión de pertenecer a esa sociedad ingresa en El Cairo School for American Children (CSAC) en 1946. El choque estético - cultural no solo lo vivió en su apariencia física, sino que se trasladó a sus costumbres y prácticas cotidianas. Mientras los "otros" llevaban sándwiches de pan blanco preferentemente cortado con mantequilla de cacahuate y jalea. Said llevaba una comida que nada de estos ingredientes contaba. No solo no formaban parte de su alimentación, sino que ni siquiera los había probado. Said, en cambio llevaba unos bocadillos de queso y prosciutto en pan shami. Su comida no era nada interesante ya que nadie le pedía. La comida, actuaba como un dispositivo de aislamiento y de desconexión ya que le truncaba la posibilidad de relacionarse con los demás.

Lo que Said nos va advirtiendo a lo largo de su obra es que tanto la espacialidad de su cuerpo como la que se expresa en los diferentes lugares van componiendo el cuadro de situación del problema de la identidad. Es a partir de allí, que nos permitimos pensar el concepto de paisaje en su obra, el cual abordaremos en el siguiente apartado.

\section{El paisaje de Said}

El concepto de paisaje en las ciencias sociales ha tomado diferentes denominaciones. Para Castillo Poveda (2016) el concepto de paisaje refiere a una idea compleja acerca de una realidad dada, difiriendo de las formas tradicionales de percibir la realidad (una separación del adentro-afuera, objeto-sujeto), y se le adjudica al entendimiento de un lugar o elemento por estudiar, la comprensión del contexto que lo envuelve, introduciendo un conjunto de apreciaciones sensoriales. Su definición por lo tanto es problemática, ya que su potencial supera los límites estrictos de su significado. Pero es en la geografía donde podemos identificar un comienzo en sus postulados teóricos. Pero a pesar de identificarla en el ámbito geográfico, dentro de ella también ha sufrido diferentes acepciones de la mano de varios autores (Humboldt, Hartshorne, Sauer, Vidal de la Blache, entre otros). Además, dicho concepto también ha formado parte de otros ámbitos disciplinarios, pero para no apartarnos del tema traeremos algunas definiciones de la mano de tres autores/as. 
Para Santos (1996) el paisaje no se crea de un día para otro, sino que se compone de un conjunto de objetos con edades diferentes y de herencias de muchos momentos temporales. Pero para el autor debemos superar la materialidad superficial del paisaje (su fisonomía) para llegar a su significado. “La percepción no es aún conocimiento, que depende de su interpretación y será tanto más válida cuanto más limitemos el riesgo de considerar verdadero lo que solo es apariencia" (Santos, 1996:60). Santos además intenta llevar claridad a categorías de la geografía que muchas veces por su estrecha relación se dificultan definir sus relaciones. En este sentido el autor nos plantea que el paisaje es diferente al espacio. El primero es la materialización de un instante de la sociedad. Mientras que el espacio es el resultado de la suma y la síntesis, siempre elaborada del paisaje con la sociedad a través de la espacialidad. En este sentido, el paisaje permanece y la espacialidad sería un momento. El paisaje es relativamente permanente mientras que la espacialización es mutable, circunstancial, producto de un cambio estructural o funcional (Santos, 1996). Para Silvestri (2003) existen dos acepciones sobre el concepto de Paisaje. Una que la define como fragmento de un territorio. Y otra que se define por su representación visual. “En la primera acepción, utilizada por la geografía, el hombre se comporta como actor, transformando el ambiente vivido; en la segunda, como espectador que observa y comprende el sentido de sus propias acciones. En cada definición permanece, en sordina, la otra: la primera no puede desligarse de la apreciación perceptiva, eminentemente visual; la segunda -la imagen, representación - no existe en ausencia de un referente real, y de un trabajo simbólico realizado socialmente" (Silvestri, 2003: 40).

Las dos propuestas de los autores (Santos y Silvestri) nos permiten comprender al paisaje como una categoría que está fuertemente vinculado a la dimensión temporal, a la transformación material y simbólica del espacio. Y que antes de hablar de paisaje, la discusión y el debate debe estar centrado en el espacio. Un espacio que se transforma a partir de diferentes procesos materiales como inmateriales. Inmateriales porque los discursos también generan transformación en los territorios. Las geografías imaginadas generan no solo acciones concretas en los territorios sino también formas de representación donde los actores se identifican o se sienten excluidos. Por su parte Claval (1995) sostiene que existen cinco acciones que permiten a los actores reconocerse en el paisaje como así también comprender como se produce el mismo:

1. Reconocerse: en una porción de un territorio nos obliga a (re) descubrir las raíces que nos ligan a él. Se busca entretejer una identidad entre la sociedad y el espacio.

2. Orientarse: implica saber cómo desplazarse en el interior de cada territorio.

3. Marcar: un lugar consiste en imponer sobre el espacio rasgos materiales y simbólicos que permitan generar canales de orientación.

4. Nombrar: consiste en generar una toponimia determinada, nombrando a los diferentes lugares y de esta manera impregnarlos de cultura y poder.

5. Institucionalizar: el lugar quiere decir conferirle un significado colectivo, otorgarle repitencias de un ritual secuencial, racionalizarlo para adminístralo y utilizarlos. También consiste en clasificarlo e imponerle una connotación determinada.

En estas cinco acciones podríamos trasladar la propuesta de Claval a la obra de Said.Sin realizar un análisis pormenorizado en el sentido estricto de esta propuesta podemos inferir que las cinco acciones se encuentran preconfiguradas por el colonialismo y el discurso orientalista. Said no logra reconocerse en el paisaje del Cairo ya que el espacio que lo recepta está fuertemente impregnado o marcado de una carga colonial. Tampoco consigue orientarse en los territorios que habita ya que los únicos lugares que él se siente seguro son los espacios introspectivos. La presencia colonial no solo se da en lo militar, sino también a través de las diferentes institucionalidades que los 
británicos diseñan para constituir su presencia y dominación. Said se desenvuelve en un espacio no solo modelizado sino administrado y dotado de significados externos.

\section{La Nación en tiempos y espacios heterogéneos}

Raymond Williams (2000) en su trabajo Palabras claves: un vocabulario de la cultura y la sociedad nos presenta una propuesta muy interesante que va más allá de la confección de un glosario. Sino como manifiesta el autor su obra se basó en el registro de investigación sobre un vocabulario. Dentro de las palabras (de una selección de términos que van de la $\mathrm{A}-\mathrm{V}$ ) el autor nos aclara que, si bien los temas académicos no son categorías eternas, pudo observar que la riqueza no se encontraba en las disciplinas independientes sino en la discusión general de los términos. En este sentido una de las palabras de dicho registro es el de nación. Este concepto ha sido de uso común desde fines del siglo XIII asociado originalmente con un sentido primario de grupo racial y no de grupo políticamente organizado. Por ello, el autor nos advierte de la evidente superposición entre ambos sentidos, el cual dificulta precisar el surgimiento del sentido moderno de la formación política. Para principios del siglo XVII, la nación hizo referencia a todo un pueblo del país (Williams, 2000).

En este trabajo, más allá de esbozar algunas referencias al origen del concepto nos interesa tratar de presentar otras miradas sobre la categoría de nación más allá de la mirada Occidental, como así también superar el monopolio de la territorialidad que imprime el Estado - Nación. Por lo cual, consideramos que es importante trabajar con autores que no solo pongan en tensión su composición occidental, sino que a su vez reconozcan en ella sus limitaciones y perspectivas para los territorios no europeos.

Desde la perspectiva occidental, el abordaje político de esta categoría nace de una fuerte y estrecha vinculación con la cultura monolítica y homogénea, impuesta sobre un espacio vacío a la espera de ser dotado de identidad y significado. Pero el tiempo de la Nación es un tiempo desigual que responde a las diferentes experiencias de los grupos sociales. Hablamos de temporalidades y experiencias diferentes que buscan (des) institucionalizarse en el espacio. Para Chatterjee (2008), Benedict Anderson ${ }^{4}$ incorpora demasiadas esencializaciones que hay que cuestionar, ya que no responde a las diferentes realidades que se encuentran inmersas las comunidades. Para los estudios subalternos, hablaríamos de una "Política de la heterogeneidad" ya que los gobiernos no cumplen el discurso de igualdad. En este sentido, no se puede sostener la idea de valores esenciales sino de estrategias contextuales, históricas y siempre provisionales. Chatterjee asiente que si bien se parte de la imposición o de la idea de afiliaciones universales, de ningún modo desaparecen las identidades particulares. Pero la cultura es el resultado de un proceso inacabado de construcción de identidades llevado a cabo por las personas a lo largo del tiempo. Este proceso establece las categorías con las que individuos y sociedades analizan la realidad siempre partiendo de una escala local (Claval, 1995).

En síntesis, podemos plantear que comprender la Nación como un categoría dinámica y heterogénea, nos permite comprender que las identidades (por fuera de las perspectivas esencialistas) y las configuraciones culturales generan nuevas formas de construcción de fronteras culturales. Pensar a la Nación en este sentido como plataforma de configuración de un paisaje de identidades en construcción (múltiples y superpuestas) nos permite abordar la obra de Said desde una perspectiva descentrada del orden espacial hegemónico occidental.

El concepto de Nación es una categoría que, si bien no requiere exclusivamente una dimensión territorial, posee la capacidad (política) de búsqueda de un anclaje territorial, como así también de una representación cultural. Esta idea la refleja Appadurai (1997) en su ensayo Soberanía sin territorialidad. Notas para una geografía

4 Hace referencia a la obra “Comunidades imaginadas. Reflexiones sobre el origen y la difusión del nacionalismo” del año 1983. 
posnacional. En ese trabajo el autor discute la crisis del Estado-nación a partir del problema de la territorialidad a través de diferentes fenómenos emergentes en los territorios como los nuevos nacionalismos, los grandes movimientos migratorios, la producción de localidades, el surgimiento de translocalidades y la fuerza de identidades trasnacionales, entre otras cuestiones. Todos estos fenómenos que se dan dentro (y fuera) de los límites impuestos por los Estados Nación cuestionan la idea de la soberanía territorial vinculada al Estado, la cual está cada vez más divorciada del concepto tradicional de nación. "Quizá la mayor peculiaridad del Estadonación moderno fue la noción de que las fronteras territoriales podían mantener indefinidamente las fábulas de singularidad étnica" (Appadurai, 1997:109). Por último, el concepto de nación en los términos tradicionales, también se enfrenta a la crisis de la metáfora insular (Grimson, 2011). Para Grimson son tres fenómenos sociales los que resquebrajan la metáfora del archipiélago. El primero se refiere a los procesos de independencia de los territorios de Asia y Âfrica en donde fue inverosímil seguir sosteniendo la idea de uniformidad o "pureza preservada" de esas sociedades. En segundo lugar, los procesos migratorios (y sobre todo las comunidades transnacionales) derribaron las ideas y modelos de "islas culturales". Por último, el rol de la tecnología y los medios de comunicación en donde los símbolos y mensajes se desplazan. En este sentido, los dos últimos fenómenos sociales generaron un proceso de interconexión permanente y a gran escala.

\section{Desterritorialización y/o multiterritorialidad del paisaje}

Haesbaert (2011) en su libro El mito de la desterritorialización. Del "fin de los territorios" a la multiterritorialidad nos acerca una interesante propuesta para rastrear estos conceptos. En primer lugar, el autor nos advierte que la geografía en primera instancia estuvo distanciada de la discusión de este término y fue apropiada por las ciencias sociales las cuales postularon el fin de los territorios de la mano de los procesos de globalización. En relación con esta argumentación Haesbaert sostiene que vivimos un pasaje a la multiterritorialidad, y que más allá de pensar en procesos de disolución del territorio, asistimos a nuevas formas de territorialidad. También en cuanto al término de desterritorialización desmonta el mito de que el Estado sea el principal agente de territorialización. Al explicar las dinámicas y acciones que el Estado despliega sobre los territorios podemos evidenciar que en realidad se generan procesos de des-re-territorialización formando instancias simultáneas de destrucción - creación. Por último, al rastrear el concepto de desterritorialización Haesbaert encuentra que este concepto ha sido trabajado por diferentes disciplinas, pero considera que la “(...) concepción teóricamente más elaborada sobre desterritorialización proviene de la filosofía, como uno de los conceptos centrales del postestructuralismo de Gilles Deleuze y Félix Guattari" (Haesbaert, 2011: 28)

Haesbaert (2011) sostiene que hay que definir primero el territorio para entender los procesos que se suscitan sobre él. "Territorializarse, pues, significa crear mediaciones espaciales que nos proporcionen un efectivo poder sobre nuestra reproducción como grupos sociales (para algunos también como individuos), poder que es siempre multiescalar y multidimensional, material e inmaterial, de dominación y apropiación al mismo tiempo" (Haesbaert, 2011: 82 - 83). Pero aclara (al igual que autores como Claval) que toda acción cultural es a su vez una acción política. Por otro lado, no hay ninguna actividad, (incluso las de tipo material) que no sea al mismo tiempo productora de sentidos y de símbolos, ya que comprenden un fenómeno social, económico y político. El Estado - Nación históricamente ha estado marcado por una comunidad imaginada, donde reproducía la figura de un individuo nacional - universal capaz de imponerse sobre las diversas comunidades. Pero mientras tanto, reinventaban símbolos e identidades nacionales estructurados para consolidar la homogeneización de la nueva Nación - Estado. Esto genera un movimiento ambivalente: desterritorializador y reterritorializador a la vez ya que el Estado debe modificar los actuales registros 
territoriales preexistentes para a su vez imponer nuevas configuraciones espaciales sujetas a las propias necesidades y funcionalidades del nuevo actor territorial (colonialismo y sistema capitalista).

Las identidades modernas eran territoriales y casi siempre mono lingüísticas. En cambio, las identidades posmodernas, son transterritoriales y multilingües. Lo nacional especialmente dentro de las lógicas posmodernas contemporáneas, no siempre aparece acompañado por recortes territoriales uniformes y contiguos. Para Haesbaert, el vaivén entre espacio y cultura, territorio e identidad no es una simple manipulación simbólica o ideológica, hay detrás de ellos muchas variables para analizar. En la actualidad hablamos también de una territorialidad que se construye en la propia movilidad espacial de los sujetos y de las comunidades. Los actuales territorios se enfrentan a una doble territorialidad: los territorios red (forma espacialmente discontinua, dinámica y más susceptibles a las superposiciones) y los territorios zona: (centrados en dinámicas con sociedades vinculadas al control de superficies o partes). En este contexto ambas territorialidades buscan deslegitimarse dependiendo las necesidades de los actores hegemónicos. Pero en la actualidad en el escenario de las territorialidades continuas y contiguas están cediendo lugar al mundo de múltiples territorialidades.

Llevando estas ideas a la obra, el Estado colonial británico generó en los territorios no occidentales (en este caso El Cairo) procesos de desterritorialización a través de mecanismos de destrucción del paisaje cultural local y a su vez construyendo una nueva arquitectura hegemónica cultural. Pero la vida de Said a lo largo de los diferentes territorios que él nos narra y que se van vinculando a través de su búsqueda de identidad, se enmarcan en un espacio multiterritorial. Es en la conectividad entre los diferentes espacios que Said logra configurar un paisaje cultural de carácter multiterritorial donde las identidades (si bien reciben la misma mirada esencialista), también se va configurando en un contexto cosmopolita y emergente de espacios y actores subalternos que buscan hacerse su lugar.

\section{Reflexiones finales}

En primera instancia nos parece oportuno reconocer que la obra de Said es mucho más amplia y rica que lo que se puede estimular desde este artículo, el cual intentó reconstruir y complementar (con categorías externas a la obra) la trayectoria de vida del autor. Ese orientalismo corporizado en la vida de Said no logra abarcar el análisis discursivo que pretendió legarnos en sus obras. Cabe aclarar que Fuera de Lugar fue uno de sus últimos trabajos en un contexto de enfermedad que escribió con pasión y dolor y que lo llevó no solo a realizar un cierre desde una sistematización de su vida académica, sino que de alguna manera tuvo un tono liberador fuertemente retrospectivo. Es allí, donde intentamos trabajar con las categorías analizadas para recomponer la mirada del espacio, sus configuraciones, pero desde la perspectiva del autor - protagonista. La deconstrucción del discurso se expresó espacialmente en los diferentes lugares que Said tuvo que renunciar, vivir y adaptarse a lo largo de su vida. Ese fuera de lugar es el paisaje desterritorializado y multiterritorial que supo asistir.

La organización espacial en la cual se encuentra inserto Said está configurada por un territorio modelado (y moldeado) por la influencia discursiva y material del proceso (neo) colonial. Es a partir de esa configuración territorial que Said habita los diferentes lugares que transita en la obra. Es decir, se desenvuelve en lugares preconfigurados por fuerzas externas, las cuales terminan provocando en Said estrategias de adaptación o de exilio permanente. Pero no solo no lo logra, sino que tampoco consigue acceder al proceso de asimilación de la sociedad (externa) dominante. Said forma parte de un otro territorial que tiene que estar allí para sostener la asimetría cultural. Su tan ansiado proyecto de invisibilidad termina fracasando ante el proyecto 
de visibilización forzada y travestida ${ }^{5}$. Es más, debe ser y estar visibilizado para que la cultura dominante pueda simbólicamente existir e imponerse. Retomando las propuestas de Santos y Silvestri, podemos entender que el paisaje está atravesado por diferentes temporalidades. La matriz cultural está inscripta en el espacio, pero el paisaje de la obra analizada solo refleja la sacralidad europea dejando de lado cualquier rastro ajeno a esta representación. En ese sentido, Said no encuentra reparo en esta definición, ya que los sentidos que él intenta cotejar en sus entornos están construidos previamente. $Y$ es allí, donde el concepto de desterritorialización ocupa un lugar en el análisis del trabajo. La acción del Estado colonial lo convierte en el primer actor de desterritorialización, ya que modifica el espacio materialmente a su voluntad despojándolo de su carácter natural, político y cultural en pos de satisfacer en primera medida sus necesidades como extensión de la metrópoli. Pero ese proceso no solo afecta la configuración de carácter territorial sino también perturba la de carácter simbólico. El poder material y discursivo son a fin de cuenta los motores de este proceso.

Por último, podemos trazar la continuidad de este trabajo pensando en qué medida lo acaecido en la vida y narración de Said, no se está (todavía) replicando en otros rincones del mundo. Como existen hoy diferentes habitantes y comunidades que se encuentran despojados de sus hábitats siendo extranjeros en sus tierras natales, mientras otros son obligados a renunciar a su condición de ciudadano para formar parte de las filas de migrantes itinerantes, o como no sufriendo ninguna de las dos anteriores condiciones de vida, uno puede aún encontrarse desterritorializado en la actual configuración de una sociedad cada vez más alejada de las identidades primigenias de la comunidad y la cultura.

\section{Bibliografía}

Appadurai, Arjun (1997). Soberanía sin territorialidad. Notas para una geografía posnacional. En: Novos Estudos $N^{o}$ 49, 11/1997, Cebrap, San Pablo, pp. 33-46; y originalmente lo ha sido en P. Yeager (ed.): The Geography of Identity, University of Michigan Press, Ann Arbor, pp. 40-58.

Carreras, Alejandra Silvia (2016). Literatura del yo: reflexiones teóricas perspectivas de autor en el género autobiográfico. Kañina, vol. 40, núm. 2. Universidad de Costa Rica.

Castillo Poveda, Manuel Alejandro (2016). Contextualización histórica del concepto de paisaje, sus implicaciones filosóficas y científicas. Rev. Filosofía Univ. Costa Rica, LV (143), 11-24, septiembre-diciembre/ ISSN: 0034-8252

Clifford, James (1999). Itinerarios transculturales. Barcelona. Editorial Gedisa.

Chatterjee, Partha (2008). Capítulo 4. La utopía de Anderson. En Partha Chatterjee, La Nación en tiempos heterogéneos y otros estudios subalternos (pp 107-123). Buenos Aires. Editorial Siglo XXI.

Claval, Paul (1995). La Geografía cultural. Buenos Aires. Editorial Eudeba.

Grimson, Alejandro (2011). Los límites de la cultura. Crítica de las teorías de la identidad. Buenos Aires. Siglo XXI editores.

Haesbaert, Rogerio (2011). El mito de la desterritorialización. Del "fin de los territorios" a la multiterritorialidad. México. Editorial Siglo XXI.

Mbembe, Joseph-Achille (2016). Crítica de la razón negra. Ensayo sobre el racismo contemporáneo, trad. de Enrique Schmukler. Barcelona, España: NED Ediciones

Said, Edward (1999, 2001). Fuera de lugar. Barcelona. Editorial Debolsillo.

5 Mbembe (2016) en Crítica de la Raza Negra relata y describe cómo se comporta el hombre blanco en relación con la raza negra. El autor habla de diferentes estrategias de invisibilización y rechazo. Entre ellas podemos mencionar, la lógica del cercado y el rechazo a ver y al ser. Solo lo identifican al negro a través de práctica de denigración y travestimiento" (disfrazarlo) y de ese modo logran extraerlo del mundo salvaje a través de la decoración. Es decir, deben sacarlo de contexto para cargarle nuevos significados. 
Said, Edward (2002). Orientalismo. Barcelona. Editorial debolsillo.

Said, Edward (2018). Cultura e imperialismo. Debate. Barcelona. Penguin Random House. Grupo Editorial.

Santos, Milton (1996). Metamorfosis del espacio habitado. Barcelona. Editorial Oikos-Tau.

Silvestri, Graciela (2003). El color del río. Historia cultural del paisaje del Riachuelo. Colección de las ciudades y las ideas. Universidad nacional de Quilmes. Editorial Prometeo.

Williams, Raymond (2000). Palabras claves: un vocabulario de la cultura y la sociedad. Editorial Nueva Visión Argentina

Zapata, Claudia (2008). Edward Said y la otredad cultural. Revista Atenea 498 Volumen (II) pp 55 - 73. http://dx.doi.org/10.4067/S0718-04622008000200005 